\title{
DESIGN WITH FLOODS: FROM DEFENCE AGAINST A 'NATURAL' THREAT TO ADAPTATION TO A HUMAN-NATURAL PROCESS
}

\author{
L. HOBEICA ${ }^{1} \&$ P. SANTOS 2 \\ ${ }^{1}$ Institute for Interdisciplinary Research, University of Coimbra, Portugal. \\ ${ }^{2}$ Centre for Social Studies, University of Coimbra, Portugal.
}

\begin{abstract}
Recognizing that traditional flood management interventions focus on defence, attempting to eliminate contingencies in the urban relationship with rivers, an emergent perspective, spearheaded by spatial design, seeks to deal with floods through a more holistic framework. In contrast to the prevalent 'design against floods' approach that targets either the hazard or the exposure components of flood risk, 'design with floods' focuses as well on the assets at stake (including the built envelopes of exposed people and activities, usually covered under the term vulnerability), duly acknowledging the intertwining of natural and human processes. Using a multiple case study comprising three European flood-prone urban projects, we explore potentials of spatial design as an adaptation tool that goes beyond flood protection to foster wider societal gains. Our analyses have so far suggested that 'design with floods' requires a positive stance through which problem-solving and sense-making approaches are merged to provide both safety and urbanity (enriched urban realm and experience), without eliminating floods per se, accepted as a complex hybrid process.
\end{abstract}

Keywords: flood adaptation, riverine urban projects, spatial design, urban regeneration.

\section{INTRODUCTION}

Giving space for river waters as a flood mitigation strategy is a noticeable growing trend [1], which partially recognizes the limits of traditional defensive approaches that restrain either the river (as the hazard source) or the urban occupancy of floodplains (exposure), in the context of greater uncertainties heralded by climate change. At the same time, other environmental concerns (in part linked to the mitigation of climate change itself), such as preventing urban sprawl, have been pressing the redevelopment of floodable urban areas that have become underused in the post-industrial era [2]. In this sense, the adaptation of the new exposed structures, as a more flexible, long-term and no-regret strategy, has been advocated to reconcile the demands of flood risk management and urban development, which have clear spatial expressions [2,3]. With its general aim of enhancing existing conditions through the manipulation of form and substance of space at different scales, spatial design, meant to be an interdisciplinary professional field, can thus be a valuable tool to reach that end. But what can make spatial design successful in pursuing such a task? In this paper, we explore the relationships between spatial design and flood risk adaptation in the redevelopment of riverine urban areas, based on the analysis of three European flood-prone urban regeneration projects. 
After briefly introducing the challenges of regenerating flood-prone urban areas (Section 2), the paper presents adaptation as a flood conciliation strategy (Section 3) and spatial design as a means to foster a broader flood-adaptive approach (Section 4). The three studied cases are then briefly introduced (Section 5), followed by some general lessons that can be learned from them (Section 6). The raised insights lead us to propose a scale of flood adaptation by design (Section 7), before ending the paper with some general implications of and prospects for 'design with floods' (Section 8).

\section{URBAN REGENERATION AND THE NEED TO DEAL WITH INTRA-URBAN FLOODABLE SPACES}

As a contemporary feature of the post-industrial world, urban regeneration refers to intentionally organised initiatives to boost new life into city segments when their intrinsic vitality has given signs of decline. Despite their great inertia, cities are indeed dynamic systems that are always evolving and changing their scope and atmosphere, while some basic hard structures remain as their most long-lasting elements (even though the use and meaning of these also shift across time). Yet, when the inherent urban vigour is hampered by adverse socioeconomic trends, the regeneration of urban areas requires ad hoc strategic interventions that often take the form of comprehensive urban projects.

Being closely linked to the identity of riverine cities, riverfronts play a special role in urban regeneration initiatives, since the open horizons and the sense of naturalness attached to them currently represent valuable urban assets. At the same time, many riverine urban spaces were once a privileged location for industries and transport infrastructures now in decline, configuring actual 'bad places' in terms of remaining risks (notably floods and pollution) [4], which nevertheless need to be brought to urban life again. In fact, such brownfields are probably instead excellent places if other economic, landscape and social potentials are also considered; and this is perhaps the main reason why their redevelopment, even when they are prone to floods, is often considered as necessary $[2,3,5]$. Revamping such areas is definitely in line with the human historic settlement pattern of living by water bodies, which constitutes an important cultural heritage in itself. The regeneration of riverine urban spaces is thus a complex issue; yet it should be noted that flood proneness represents only one feature of these ever changing spaces, in which multiple and conflicting demands frequently overlay. Floods indeed represent one-off contingencies (although with probable serious repercussions) when reasonably compared with other more immediate and regular urban needs [3,6]. This does not mean that urban redevelopment should be carried out ignoring floods as a real threat, but that it should be pursued in an integrated fashion, in which overall urban life enhancement and flood protection merge into a single goal.

Standing 'at the point where nature and artifice meet' [7], cities are much more than mere concentrations of people and assets, as traditionally seen through strict flood management lenses. Presently home to half of humanity, cities - 'the human invention par excellence' [7] - should provide inspiring environments in which human life can positively unfold. Therefore, at stake in cities are not only the technical issues related to life protection in a narrow sense, but also wider necessities of the being that include experiencing life in its wholeness. In this connection, the greatest challenge in redeveloping flood-prone riverine spaces is to balance existing and envisaged short- and long-term constraints and opportunities, while keeping cities' identity and sense of place (their human face), without compromising human life in its broadest sense. The urban regeneration of such spaces thus conforms a timely opportunity to review current concepts and practices regarding dealing with floods in riverine cities. 


\section{FROM FLOOD DEFENCE TO FLOOD ADAPTATION}

Perhaps a first step towards a more inclusive approach to floods is to fully recognize them as hybrids, complex phenomena in which natural and human processes converge. Obviously, fluvial floods are not only the result of river overflows, but mostly of the confrontation of its water with human interventions (including on the river system itself), valuable assets and ultimately human life. Therefore, in spite of being included among 'natural' (hydrometeorological) risks, floods are increasingly driven by human actions, which have the power to impact equally on the hazard, exposure and vulnerability risk components. In this vein, people cannot be taken merely as fragile passive elements to be protected but also as active co-producers of flood events.

Defensive approaches to flood management, which generally aim to control either the hazard or the exposure (or both - see Fig. 1), have largely overlooked the existing feedback loops between hydrological and social processes that lead to flood events [8]. Consequently, despite centuries of flood prevention practices, flood risk as a whole has been steadily increasing. At the same time, climate change has been challenging such defensive approaches [3], which have mostly been built and developed under the paradigm of certainty. In this sense, some flood management initiatives have started to put more emphasis on precautionary measures targeting either the exposure or the vulnerability risk components, envisaged as a no-regret, more robust approach to face climate change uncertainties [3]. Accordingly, it seems that the human approach to floods has started to change: instead of endeavouring to prevent the unpreventable, the focus has been shifting towards the acceptance of flood processes, in a 'living with floods' perspective that nevertheless keeps people's safety as its prime goal [2].

While in defensive approaches floods are normally taken solely as a threat, a technical problem to be solved, 'living with floods' as an adaptive perspective entails also dealing with floods through a more positive stance. Adaptation refers thus to proactive changes in the predominant mindset, to include the recognition and exploitation of possible societal opportunities that may arise from the acceptance of flood processes. At first sight, it is not really easy to grasp any human advantage deriving from urban floods; yet, regular and minor tangible flood experiences reminding that absolute prevention is unattainable can for example be of a great value in order to plan for possible emergency situations [3]. On the other hand, these quasi disasters can have an intangible effect of repositioning cities and humankind as regards the cyclical flows of life and the unforeseen, which is totally fine-tuned with climate change prospects.

An adaptive attitude thus incurs the active anticipation of hazardous events, comprising the control of the potential disaster situations (not of the hazard itself), and even the tolerance of
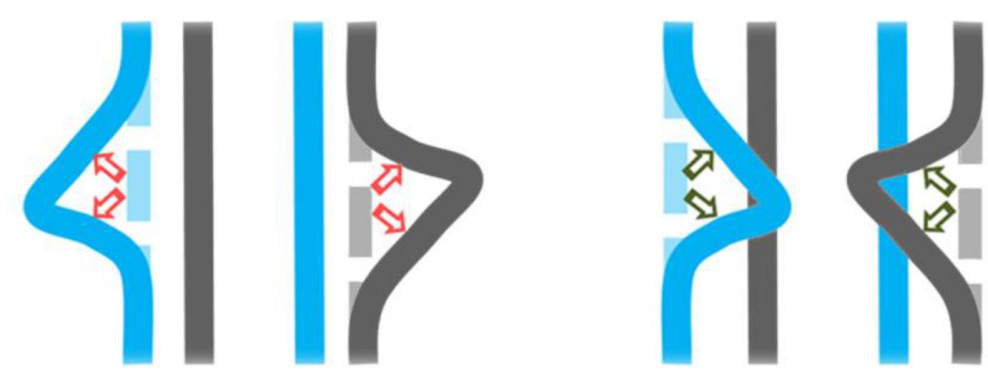

Figure 1: From defensive (left) to adaptive (right) strategies to floods. 
some disturbances from time to time. Although a controlling perspective is still present - and must always be, whenever people's life is at stake -, it is not river processes that are subject to it, but a more complex entity that integrates water and human dynamics. Adaptation certainly requires a thorough understanding of the flooding conditions at two distinct and complementary scales. At a lower scale, it is important to grasp the hydrologic behaviour of the watershed as a whole (in particular the rainfall-runoff relationship), which continually interplays with human-driven impacts such as land-use changes, soil erosion, or the introduction of retention ponds or dams. At a higher scale, hydraulic determining factors (topography, soil permeability, underground flows, surface roughness, physical barriers and flood defence functioning) translate the fluvial flow into the floodable area at the floodplain level, being more directly influenced by urban project interventions.

Nonetheless, adaptation should not be seen as a one-size-fits-all strategy that will finally free cities from nuisances related to flood risk [2]; its limitations lie exactly in the very hybrid trait of floods. For example, rapid-onset riverine floods surely pose additional challenges to 'living with floods', as the water depth, velocity and sediment load might imply too dangerous conditions that should, of course, be kept away from people's experience. Also, since this acceptance perspective goes in the opposite direction of the prevalent flood defence strategies, strong cultural barriers and organizational inertia should not be overlooked. Such social constraints may indeed be as important as river dynamics themselves to embrace an adaptive track.

\section{SPATIAL DESIGN AS A MEANS TO FOSTER A FLOOD ADAPTIVE APPROACH}

As a human-natural process that is permanently being constructed, fluvial floods could be regarded as an 'unconsciously designed' condition. Yet, design as an activity largely refers to the mental plan or the deliberate conception of artefacts (in terms of both form and substance) that aim to make human life and activities easier; meanwhile, the term design covers both the process of reaching such artefacts (design as a means) and the final output itself. The core of design has been to tackle complex issues through the adoption of solution-focused strategies, which may indeed challenge the problems initially posed. From a spatial design point of view, floods should be dealt with differently in regard to other site constraints such as noise or ground pollution. While the latter may be taken only as technical issues calling for solutions, floods potentially have positive aspects to be environmentally, socially and aesthetically explored. At the same time, it is noteworthy that when traditional spatial design restrictions are dealt with through an approach that is not strictly technical and reduced to efficiency, the ensuing design response tends to be more sensitive and innovative, adding value and meaning to such spaces. For example, London's future Garden Bridge was designed by Thomas Heatherwick and Arup not only as a crossing over the Thames River but also as an urban landmark and a linear garden in which biodiversity will be allowed to flourish [9].

Considering that it is possible to design 'in a unitary mode, beyond simple dichotomies of nature and culture', Prominski proposes the concept of 'andscape' to refer to the state or the condition of unity, which takes into account the overall dynamic relationships between living and non-living organisms and their environment, all of them encompassed within our cultural-natural world [10]. The notion of 'andscape' thus seems to go hand-in-hand with the emerging field of socio-hydrology [11], focused on the intertwining character and co-evolution of social and hydrological processes. Although being primarily conceived to address and communicate 'the synthetical, integrative character of landscape architectural design' [10], 
'andscape' can be a suitable guiding concept to all design situations in which nature and culture come together.

Starting from such conceptual framework, we propose to explore a 'design and floods' stance, examining the possibility of a reflexive relationship between these two processes, in which they would feed one another. Therefore, 'design and floods' contrasts with the dominant 'design against floods' mindset, usually geared towards the development of defensive structures that create barriers and even lower the sense of urbanity. It also aims to expand the 'design for flood risk' alternative [5], which still put floods (and keeps the negative term risk) in an unnecessary central position in relationship to other urban issues and does not really shed light on floods' human dimensions. In fact, both 'design against floods' and 'design for flood risk' can be equated to problem-solving approaches that somehow understate the design remit of uncovering new issues and raising new meanings to usual situations. We thus argue that 'design and floods' should embrace such a holistic and not strictly technical endeavour, through a positive adaptive stance. In this sense, besides acknowledging flood as a hybrid, it requires to fully recognize urban spaces as places, that is, territories with meaning to human life. Hence safety and urbanity (place-making) should be at the core of 'design and floods', which implies the challenge of strengthening visual and physical links between cities and urban rivers, and even providing access to water whenever possible [5].

\section{5 'DESIGN AND FLOODS': THREE URBAN PROJECTS}

To explore possible synergies of 'design and floods', our research has focused on flood-prone urban regeneration projects (and not on flood management projects that, due to their location and scope, happen to have multiple functions and present an urban character). The three studied cases were intentionally selected to cover diverse situations (see Fig. 2), and comprise:

- an intra-urban riverine green park along both riverbanks of the Mondego River, in Coimbra, Portugal (already partially implemented);

- a flood-compatible intra-urban neighbourhood nearby the Garonne River, in Bordeaux, France (detailed design is still ongoing); and

- an intra-urban flood defence infrastructure bordering the Scheldt River, in Antwerp, Belgium (implementation is ongoing).

It was only in the 1980s, when a system of dams and river training works were finalized, that the Mondego River lost its highly fluctuating nature, which had up to then secured large unoccupied intra-city parcels. A new stable landscape, with a permanent storage pond in the centre of Coimbra, was then the centrepiece of a regional park project, spanning both
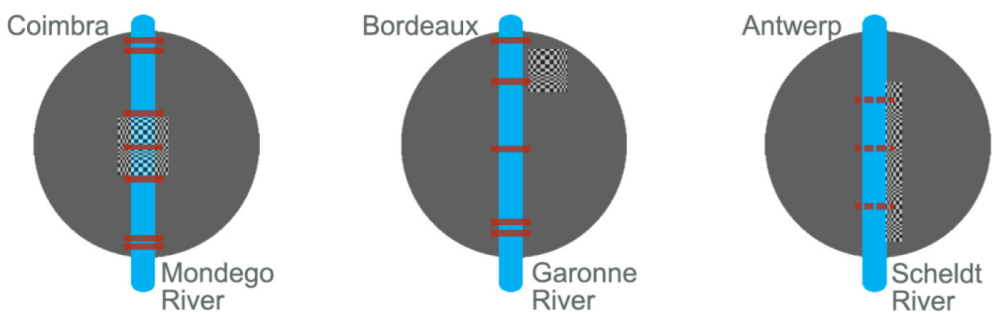

Figure 2: Spatial characterisation diagram of the three studied interventions. 
riverbanks. An international competition in the mid-1990s, won by the MVCC agency, has initiated a long-term process of urban riverfront creation. The competition brief overlooked the susceptibility of the area to floods, probably due to the newly implemented regulation works and to the fact that the envisaged project was a green urban park, mostly with lawn areas and some ancillary buildings. The idea of floodplain was indeed taken as obsolete: the site was then referred to as 'the old floodplain of the Mondego River' [12]. Yet, in 2001, when a first section of the park was being implemented, an 'unexpected' flood event revealed that such perception was biased. This event has triggered structural and programmatic changes in the design output, while the attainment of a fixed safety level was the main recommendation; the previous strategy of fostering the lowest exposure was kept. A singular green urban riverfront was subsequently achieved, marked by its close proximity to the river, and has since been intensively used; yet, although the river is allowed to (re)occupy the prairie during its occasional overflows, water was overall treated as a static element of the urban scenery.

Since the 1990s, Bordeaux has been trying to reconquer the Garonne riverbanks, a process that started on the left bank and has more recently expanded to the right one. The construction of a new bridge linking two major urban redevelopment zones in the North brought to light the strengths of Brazza, a typical declining industrial urban fringe, rightly in the centre of Greater Bordeaux. From 2010 on, Brazza has been subject to a sequence of planning phases, with flood proneness being recognized by the city authorities as one of its main constraints, besides ground pollution. In contrast to most of Bordeaux's riverbanks, this area is not protected by a dyke; therefore, adapting to floods has been taken as a driving concept behind all the design proposals, the latest one elaborated by a team led by the YTAA agency. Anticipating upcoming (stricter) flood regulations (the current ones are considered outdated), two main concepts were adopted to adapt the new neighbourhood to floods: minimal alteration of the local topography, and hydraulic transparency of and between buildings. Such approach aims at the same time to protect the site's future population and not to engender greater flood risk to adjacent urban areas. In terms of urban design, this is reflected in three wide green strips perpendicular to the river, which allow nature (including the river overflows) to enter into the quarter; two main building typologies (on stilts and with floodable undercrofts) also favour such encounters with minimal damages. These simple and passive solutions were driven by the logic that 'water must be seen' within the neighbourhood during floods, as stressed by the involved lead engineer [13].

The 2005 update of the Sigma flood protection plan for the whole Scheldt estuary, with its foreseen physical barriers putting under threat the remaining contact between city and river, called for a reinterpretation of Antwerp's wasted land along the right bank. A restricted international competition was jointly promoted in 2006 by the city of Antwerp and Waterwegen en Zeekanaal NV (the Flemish waterway administration agency) to gather insights on how to equate urban character (the riverfront's sense of place) and flood defence, while the existing quay wall should be treated as an urban heritage. Considering that behind every problem 'lies an opportunity to prepare a project, and the bigger and more complex the problem is, the more extraordinary the opportunities are for finding unusual solutions' [14], the PROAP-led winning team put forward a flexible proposal for the reclamation of the riverfront, with some guiding principles instead of a defined master plan. Spatially adapted to the river's dynamics, this proposal tackles multi-objectives at once and is, by nature, eventually adaptable to ever-changing societal needs. An open design process has led to an output that is a composite defensive structure - a civil element, consisting of dykes, floodwalls and movable devices -, which nevertheless 
does not constitute a physical or visual barrier. On the contrary, it functions as well as a civic urban element [15], a riverine promenade through which the relationships between city and river are renegotiated, while the moods of the river can be further experienced (for instance, increasing the accessibility to the water).

\section{FROM 'DESIGN AND FLOODS' TO 'DESIGN WITH FLOODS'}

These three cases exemplify a 'design and floods' perspective, even if the intensity of this interaction is quite different in each of them. Of course, their overall context and flood processes are not comparable (fluvial floods in Bordeaux and Antwerp are also influenced by tides and storm surges), nor are the related design outputs. Yet, the local stance towards floods may be taken as the key feature that somehow connects them, being thus a significant aspect of pursuing 'design and floods' as an integrated approach. Considering that it underlies the design context, process and product of these urban projects, the stance towards floods was then explored, among others, through the contents of the design briefs, the profiles of key involved actors and the actual proposed layouts. As already stressed, the very traits of the flood risk also shape such stance.

Regarding the three competition briefs, while floods were rather underestimated in the case of the green park around the Mondego, they were in contrast highlighted as an important site constraint for redeveloping the Brazza sector; for the Scheldt quays, floods were even the raison d'être of the ambitious local regeneration project. The fact that this initiative has been partaken by a waterway agency potentially anticipates an integrated planning process. As a consequence, in this case floods could be taken as an opportunity to envision the quays as a decompressing space between city and river [14], in which both could temporarily and plentifully manifest themselves. In the Coimbra case, the susceptibility of the riverbanks to floods was also perceived as the opportunity that had guaranteed such a large undeveloped parcel within the city centre; yet, such opportunity was only partially capitalized by the design of the green park.

On the other hand, floods were not exactly viewed as an opportunity in Bordeaux, but pragmatically taken as a condition that had to be duly accounted for to make feasible the revamping of that area, as formally required by existing flood regulations. In fact, this is the only studied case in which permanent urban activities (including housing) are planned in a floodable zone, while in the other two mostly temporary uses are envisaged, in recognition of the transient nature of riverine urban spaces. In any case, the proactive attitude towards floods shown by the local authorities in Bordeaux results from both the vast intra-urban floodable area under regeneration (the scope of the challenge has been an important driver for flood adaptation) and the gradual development of in-house expertise on the subject (a major asset that is also possible to identify within the Brazza design team). Actually, two complementary factors were fundamental for raising awareness to floods: the overall impacts of the storm Xynthia (2010) on the French Atlantic coast and, more locally, the results of an archaeogeographical study for the Garonne right bank (2010), which recalled the strong role that water had held in configuring such territory [16].

All three cases had an explicit problem to solve involving flood management and urban development; as such, the three ensuing design outputs present simple layouts that withstand flood events, responding as well to other issues such as implementation costs or operationalization. Yet, in Antwerp and Bordeaux, the problem-solving approach was clearly geared towards a more complex and process-oriented perspective, as witnessed by the openness of the design practice: the final outputs were not fully anticipated in both cases, being allowed 
to evolve along with societal needs. For example, the elaboration of design proposals for the Brazza quarter has been supported by several rounds of iterative investigations of spatial alternatives coupled with flood modelling, gathering diverse categories of spatial designers (engineers, urbanists, architects and landscape architects). Such dynamic design processes could have been encouraged by the fact that these two cities already experience on a daily basis river variations due to sea tides, which keep people's awareness of riverfronts as an unstable (and possibly vibrant) urban setting. Conversely, in Coimbra, the Mondego's seasonal variations - which in the past were more intense and perceived as undesirable - were drastically pacified after regulation works, leading to the fading of the pre-existing flood risk culture [17]. The new apparent 'stable' condition of the river has likely induced an underestimation of flood-related human and natural processes, namely the unmanaged silting problem, which is presently the main factor behind more intense damages within the green park and the nearby areas traditionally exposed to floods.

Although arising from a coupled flood management and urban development demand, 'design and floods' may not correspond to an actual intertwining of these two processes, which can be perceived and performed as parallel ones, as shown by the Coimbra case. As a result, since the accomplishment of the green park, flood events (even minor ones) are locally misinterpreted as a failure of both the management of the dams' system and the park's design. Conversely, in a deeper 'design and floods' perspective, experiencing minor and manageable floods is taken as a mechanism for preserving the much needed flood risk culture [3]. In fact, spatial design is not a self-referencing tool: the goal of bringing together design and floods must be intentionally pursued by local authorities, territorial players and all stakeholders involved in the redevelopment of a flood-prone urban area. For example, in the cases where such interlinkages were explicitly required by the commissioners since the design brief, 'design and floods' has indeed extrapolated the problem-solving approach to reach a more thorough adaptive stance that fosters the sense of urbanity, enriching thus the urban realm and experience with floods. When the design task was performed as a dynamic endeavour that consciously integrated flood processes themselves as a compositional element, 'design and floods' eventually evolved into a more intense 'design with floods', in which these two processes somehow transcend their respective precincts to synergistically merge as one comprehensive process.

\section{DEGREES OF FLOOD ADAPTATION BY DESIGN}

The three analysed cases have clearly shown that 'design and floods' can never be a straightforward stance, being completely dependent on the existing human-natural context behind each particular urban project (i.e., on people, place and processes). In any case, 'design and floods' remains a search for an acceptable and sustainable compromise between safety and urbanity. In this sense, we have carried out an extrapolation exercise, based on the lessons that could be learned from the cases, as a means to propose a tentative scale to qualify the different degrees of flood adaptation by design. Such a scale does not intend to express various levels of urbanity and safety by design, but the growing intensity of the interactions between these two design components (see Fig. 3):

- Tolerating floods: the most basic level of 'design and floods', with no clear signs of interaction. In the Coimbra case, despite the high level of urbanity attained, not much room was left for experiencing river dynamics; instead, a sense of resignation seems to have led to the tolerance of water overflow within the new park area. 

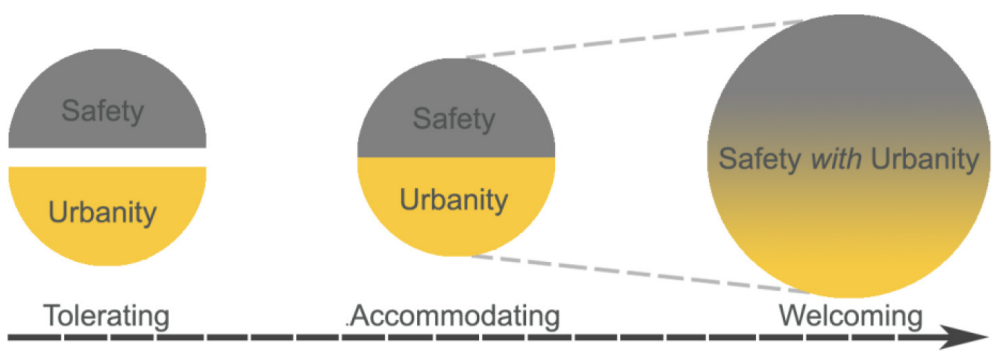

Figure 3: Different degrees of flood adaptation by design - from coexistence (left) to integration (centre) to synergy (right).

- Accommodating floods: from this point on, we can distinguish a 'design with floods' approach, with visible interactions between the two dimensions. This is best illustrated in the Bordeaux case, through its pragmatic pursuit of hydraulic transparency (preserving thus the space needed for the occasional Garonne overflows).

- Welcoming floods: the most challenging level, given spatial and cultural restrictions, yet in which 'andscape' can be exercised at its best. A synergetic stance is thus clearly portrayed. In the Antwerp case, even if a defensive device was the intended design output, the welcoming perspective could unexpectedly be attained, thanks to the fostered close and intense relationships between design and floods.

In any of these adaptation levels, damage and disturbance are not impeded from happening, although they should be kept to a minimum; yet, at the higher end of the scale (welcoming floods), overall benefit is also obtained: for instance, disturbance introduces a new temporary wet landscape, resulting in a more diversified and dynamic urban realm. According to the specificities of each case, tolerating, accommodating and welcoming floods can nevertheless coexist in the same urban project; for example, in Brazza, having urban agriculture plots placed under the buildings on stilts could be understood as a welcoming floods sign, since they can somehow benefit from the nutrients sporadically brought by the river. Also, welcoming floods cannot be directly taken as a desired approach, since it may be unfeasible in some circumstances. In any case, this is probably the most difficult level for spatial designers, since welcome implies a double design request that anticipates both dry and wet scenarios. Such spatial flexibility, which must be the rule as a means to face uncertain futures, is only attainable through a truly interdisciplinary design practice.

\section{FINAL CONSIDERATIONS}

'Design with floods' ideally means futureproofing riverine cities vis-à-vis the climate change prospects, requiring thus blurring barriers, not only with respect to human and natural processes, but also disciplinary fields. In fact, spatial design can only be successful in its task if carried out as a negotiation platform in which all the concerned stakeholders act consciously as 'flood designers'. This is certainly not yet the mainstream; but just as other environmental issues that are today taken for granted have required decades to be internalized into planning practice, time has now come for the gradual improvement of riverine urban projects through the positive incorporation of floods $[13,16]$. The analysed cases indicated that the promotion of flood risk culture is at the same time a condition for and a consequence of well-designed 
flood-adapted urban projects. A proactive flood risk culture, acting as a catalyst of involved stakeholders (including spatial designers), can indeed promote the proper understanding of the flood phenomenon and the existing urban vulnerabilities, as well as higher degrees of flood adaptation, leading to safer, more liveable and more meaningful urban places.

\section{ACKNOWLEDGEMENTS}

This study was partially funded by the Portuguese Foundation for Science and Technology, through a $\mathrm{PhD}$ grant. The authors are thankful to all designers and territorial players who generously provided information to this research.

\section{REFERENCES}

[1] European Union, Directive 2007/60/EC of the European Parliament and of the Council of 23 October 2007 on the assessment and management of flood risks.

[2] Centre Européen de Prévention du Risque d'Inondation (CEPRI), Comment Saisir Les Opérations De Renouvellement urbain pour réduire la vulnérabilité des territoires inondables face au risque d'inondation? Available at http://www.cepri.net/tl_files/ Guides CEPRI/CEPRI rapport principe amenagt.pdf, 2015.

[3] Jha, A., Bloch, R. \& Lamond, J., Cities and Flooding: a Guide to Integrated Urban Flood Risk Management for the 21st Century, World Bank: Washington DC, 2012. http://dx.doi.org/10.1596/978-0-8213-8866-2

[4] Viganò, P., Extreme cities and bad places. International Journal of Disaster Risk Science, 3(1), pp. 3-10, 2012. http://dx.doi.org/10.1007/s13753-012-0002-6

[5] Royal Institute of British Architects (RIBA), Designing for Flood Risk, RIBA: London, 2009.

[6] Rossano, F. \& Hobeica, L., Design as negotiation platform: new deals and spatial adaptation in flood-prone areas. WIT Transactions on Ecology and the Environment, 184, pp. 287-298, 2014.

http://dx.doi.org/10.2495/FRIAR140241

[7] Lévi-Strauss, C., Tristes Tropiques, Criterion: New York, p. 127, 1961.

[8] Di Baldassarre, G., Kooy, M., Kemerink, J. \& Brandimarte, L., Towards understanding the dynamic behaviour of floodplains as human-water systems. Hydrology and Earth System Sciences, 17, pp. 3235-3244, 2013. http://dx.doi.org/10.5194/hess-17-3235-2013

[9] Arup, http://www.arup.com/Projects/Garden_Bridge.aspx, 2015.

[10] Prominski, M., Andscapes: concepts of nature and culture for landscape architecture in the 'Anthropocene'. Journal of Landscape Architecture, 9(1), pp. 6-19, 2014. http://dx.doi.org/10.1080/18626033.2014.898819

[11] Sivapalan, M., Savenije, H. \& Blöschl, G., Socio-hydrology: a new science of people and water. Hydrological Processes, 26, pp. 1270-1276, 2012. http://dx.doi.org/10.1002/hyp.8426

[12] Assessoria de Planeamento e Ordenamento do Território da Câmara Municipal de Coimbra. Plano de Pormenor do Parque Verde do Mondego, Coimbra [not published], p. 1, 1999.

[13] Dunogier, C., Personal communication, Engineer, head of the infrastructure department at Ingérop's Bordeaux agency, Bordeaux, France, 2014.

[14] Nunes, J., Master plan for Antwerp waterfront. Portus, 15, pp. 68-75, 2008. 
[15] De Meulder, B., Personal communication, 5 October 2013, Architect-Urbanist, former partner of WIT Architecten, Louvain, Belgium.

[16] Scheurer, F., Personal communication, Geographer-Urbanist, Brazza project manager at Ville de Bordeaux, Bordeaux, France, 2015.

[17] Gameiro-Fernandes, J.F., Personal communication, Landscape Architect, former coordinator of the Coimbra Polis Programme, Lisbon, Portugal, 2014. 